\title{
Impact of 3D laparoscopic surgical training on performance in standard 2D laparoscopic simulation: a randomised prospective study
}

\section{Ricardo A.R. de Almeida, ${ }^{a}$ Yassar A. Qureshi, ${ }^{a, b, *}$ Alpa J. Morawala, ${ }^{a}$ Nabeel H. Merali, ${ }^{a}$ Ikechuwku Iloabachie, ${ }^{a}$ Badriya Alaraimi ${ }^{\mathrm{a}}$ and Bijendra Patel ${ }^{\mathrm{a}, \mathrm{b}}$}

${ }^{a}$ Barts Cancer Institute, Queen Mary College, University of London, London, UK; ${ }^{b}$ Barts Health Trust, London, UK

${ }^{*}$ Corresponding author at: Teaching Centre, Barts Cancer Institute, Queen Mary College, University of London, Charterhouse Square, London EC1M 6BQ, UK. Email: yassar.qureshi@uclh.nhs.uk

Date accepted for publication: 2 February 2018

\section{Abstract}

Background: Laparoscopic surgery is based on 2D imaging, with limited depth perception. The aim of this study was to analyse the impact of 3D training on the performance of surgical trainees in 2D laparoscopic simulation. Methods: Thirty medical students were randomised into group A, completing five training attempts of three modified Fundamentals of Laparoscopic Surgery tasks (peg transfer, pattern cutting, and intra-corporeal suturing) using a 3D simulator, or group $\mathrm{B}$, who were only exposed to the $2 \mathrm{D}$ platform. Time to completion, error rate, and efficiency improvement were measured. Results: The overall performance time was lower for group A than for group B, and this was statistically significant in task $2(P=0.02)$ and task $3(P<0.01)$. The mean error rate was lower for group A versus group $\mathrm{B}$, which was statistically significant for all three tasks (task 1,0 vs 0.2 ; task $2,0.4$ vs 1.8 ; task $3,0.24$ vs 1.1 ). When efficiency improvement was evaluated, group B displayed a faster rate of improvement during task $1(132.1 \%$ vs $248.8 \% ; P<0.01)$ and task $2(123.9 \%$ vs $139 \% ; P=0.15)$. For task 3 , group A demonstrated a superior rate of improvement $(190 \%$ vs $173.1 \% ; P=0.2)$. Conclusions: Introducing $3 \mathrm{D}$ training is beneficial for novices to execute 2D laparoscopic skills, particularly for complex tasks where depth perception is critical. 3D-based laparoscopic training, in conjunction with standard 2D platforms, should be introduced into surgical training to facilitate quicker and better preparation before translation of these skills into clinical practice.

Keywords: three-dimensional; two-dimensional; laparoscopic surgery; simulation training; medical education

\section{Introduction}

Laparoscopic imaging systems have improved continuously over the last two decades, with superior quality cameras and high-definition displays. ${ }^{1,2}$ However, conventional 2D laparoscopic surgery remains challenging because of practical limitations. ${ }^{3}$ The learning curve for surgeons to become proficient is distinct from that for open surgery, and thus time consuming. ${ }^{1,4}$ Features unique to laparoscopy, such as the loss of depth perception (stereopsis) often lead to erratic correctional actions that result in reduced overall surgical accuracy and efficiency. ${ }^{5-8}$ Thus, surgical performance using current 2D imaging systems has been shown to be impaired by up to $35 \%$ when compared with conventional surgery. ${ }^{9,10}$ Additional challenges with laparoscopic training include ergonomic equipment flaws, ${ }^{11,12}$ haptic feedback, and the fulcrum effect. ${ }^{1,3,4}$ Robotic surgical systems address some of these challenges but are not used sufficiently in clinical practice to necessitate dedicated training. ${ }^{13,14}$

Although the challenges of working under 2D visual conditions can be overcome with intense practice, rapid laparoscopic proficiency may be difficult to achieve for modern trainees under the constraints of modern work-time directives, and shorter duration of training. Using operating theatres for the acquisition of basic fundamental laparoscopic skills is considered unsafe, uneconomical, and unethical. Thus, simulated laparoscopic training remains a pivotal facet of surgical education. ${ }^{15}$

Stereoscopic (3D) technology has several reported advantages, including enhancing the performance of laparoscopic surgery by providing the depth perception denied by conventional 2D laparoscopy. ${ }^{16-23}$ This feature simplifies the appreciation of natural anatomical structures and provides 
a visual-spatial context to the surgical setting, facilitating the execution of complex tasks. ${ }^{19,20}$ Indeed, operative times can also be shortened, thus indicating a more efficient approach to surgery. ${ }^{24}$ However, 3D technology is associated with higher costs and is not yet widely available. ${ }^{19,25}$ Recent studies have sought to assess the differences between $2 \mathrm{D}$ and 3D laparoscopic surgical systems. ${ }^{16,18,21,26,27}$ Overall, it has been demonstrated that $3 \mathrm{D}$ vision accelerates the rate of task completion, particularly for complex tasks.

The aim of this study was to evaluate the impact of initial $3 \mathrm{D}$ training on subsequent $2 \mathrm{D}$ performance of the modified Fundamentals of Laparoscopic Surgery (FLS) training tasks by a group of senior medical students. In particular, we aimed to assess whether an initial 3D training period enhances training, and thereby reduces errors, and whether the complexity of the task is affected by the type of imaging system.

\section{Materials and methods}

This study was conducted at an academic medical centre and was planned in accordance with the Consolidated Standards of Reporting Trials (CONSORT) guidelines.
This was a prospective randomised study in which 30 participants were enrolled. Minimum participation was based on power calculations using results from previous studies at our institution. ${ }^{2}$ The inclusion criteria for participation included individuals who were new to laparoscopic surgery or simulation, did not have uncorrected visual impairments, and had committed to completing the laparoscopic training course. Candidates with laparoscopic exposure beyond camera navigation were excluded in order to mitigate differences in skill. All research participants were senior medical students with a declared interest in a surgical career.

\section{Research tasks}

The training tasks included peg transfer, pattern cutting, and intra-corporeal suturing (Fig. 1). These selected tasks were taken from the validated Fundaments of Laparoscopic Surgery (FLS-SAGES) curriculum. ${ }^{28}$ For completion of these tasks in $3 \mathrm{D}$, models previously validated at our institution were used (3D peg board, 3D pattern cutting glove, and 3D suturing glove) to allow the participant to adapt to the depth perception required in a $3 \mathrm{D}$ environment. ${ }^{2}$ The training flow was divided into two phases. Phase 1 (training) consisted of five attempts to complete each activity in 3D for group A, and five attempts to complete each activity in

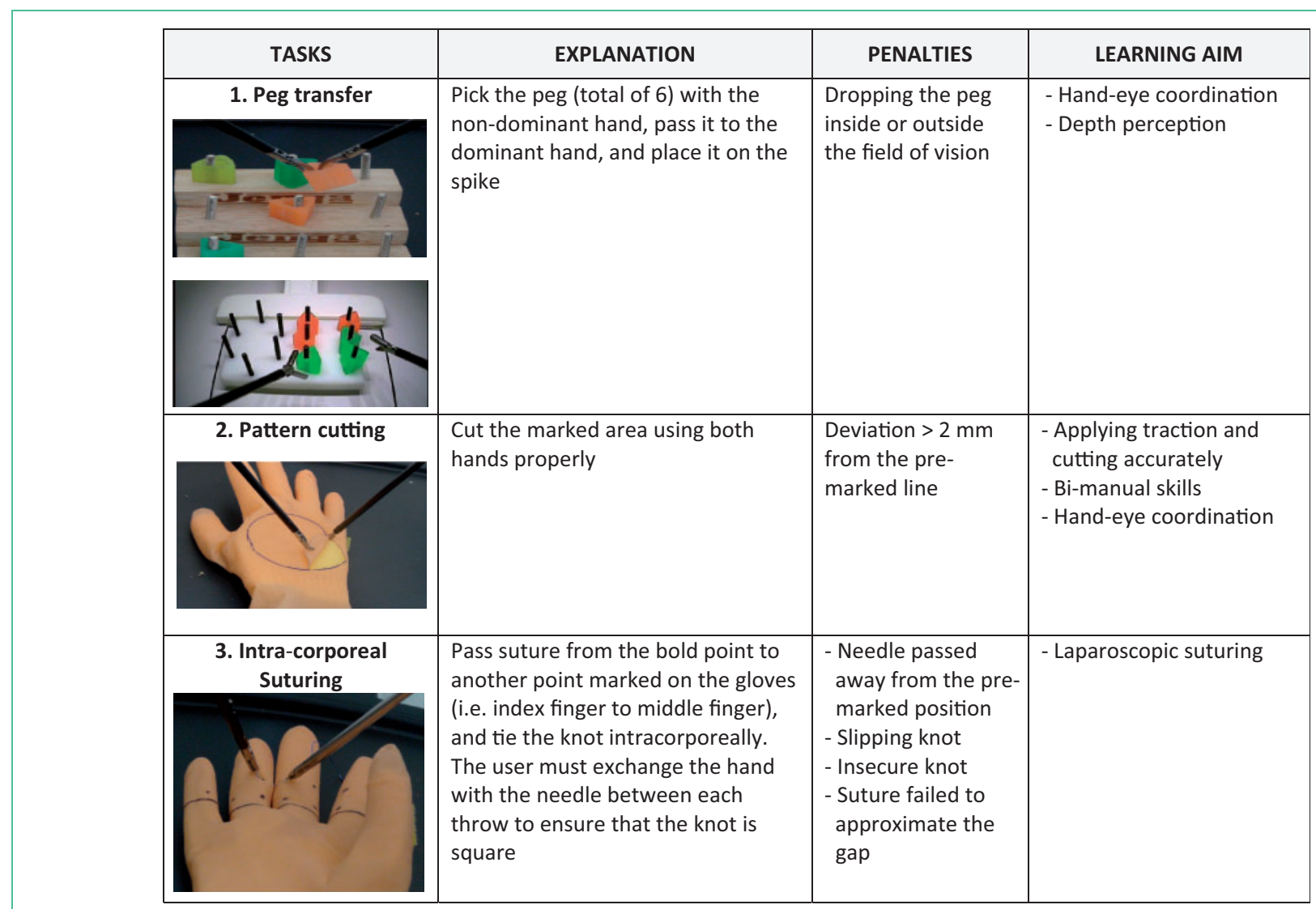

Figure 1. A description of the FLS tasks selected for this study, which include the peg board, pattern cutting, and intra-corporeal suture tasks. ${ }^{28}$ 
2D for group B. In phase 2, both groups performed each activity three times using only $2 \mathrm{D}$ imaging.

\section{Equipment}

The study was performed using the LaproTrain (Endosim, Belfast, UK) box trainer. The monitor used was an $81.28 \mathrm{~cm}$ high-definition light-emitting diode monitor (resolution, $1920 \times 1080$ pixels; motion clarity index, $400 \mathrm{~Hz}$ ) (LG Electronics, Busan, South Korea). In group A, during phase 1 , the operator wore passive polarised $3 \mathrm{D}$ glasses (weight, 16g) and used a 3D camcorder (Double Full HD, $1920 \times 1080$ Full HD 60p/24p recording) that was adapted for the box trainer through a mechanical arm (Sony Electronics, Tokyo, Japan). During phase 2 for group A, and phases 1 and 2 for group $B$, the original 2D system from LaproTrain was used (standard definition).

\section{Recruitment and training sessions}

Participants were randomised into the two groups using a computer-generated schedule. The participants received written instructions and a demonstration video for all three tasks before the first session. Candidates from group A underwent an adaptation exercise that involved looking at a static 3D image in the box trainer that alternated $5 \mathrm{~s}$ on and $5 \mathrm{~s}$ off for a minimum of $1 \mathrm{~min}$ before the start of training. Each task was demonstrated once by the same instructor, and followed by two repetitions of the exercise by the candidates. In this manner, participants could familiarize themselves with the instruments. Following the FLS guidelines and the FLS technical skills proficiency-based training curriculum, ${ }^{29-32}$ candidates started phase 1 with the peg transfer (task 1), then progressed to pattern cutting (task 2), and finally to intra-corporeal suturing (task 3) (Fig. 1). All tasks were executed in the same training/performance order. Study flow was divided into two phases with a 1-week interval in between. Phase 1 (training) consisted of a total of five attempts in 3D for group A and five attempts in $2 \mathrm{D}$ for group $\mathrm{B}$. In phase 2, both groups performed each activity three times using the $2 \mathrm{D}$ imaging system exclusively.

Because this was the index exposure to laparoscopic simulation for all participants, factors such as proficiency time or a cut-off time were not taken into account. Three parameters were considered for this study: the mean completion time, the mean error rate, and the improvement in efficiency (\%) from phase 1 to phase 2 .

\section{Statistical analysis}

Continuous variables were compared using a Wilcoxon signed-rank test, and categorical variables were compared using Fisher's exact test. Statistical analysis was performed

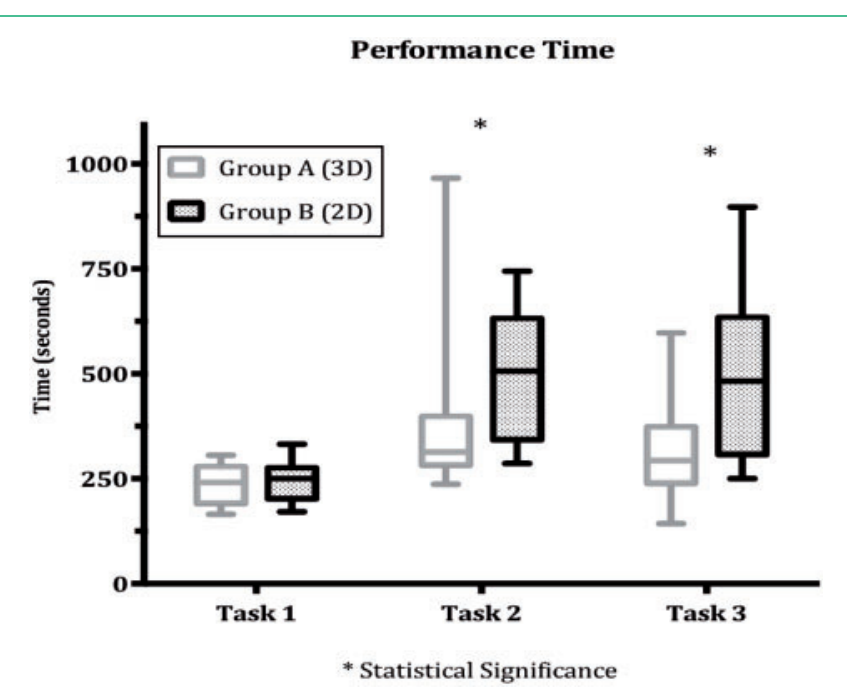

Figure 2. Differences in performance time between the 3D and $2 \mathrm{D}$ trained groups.

using Prism software (GraphPad, La Jolla, CA). A $P$ value $\leqslant 0.05$ was considered statistically significant.

\section{Results}

The study was completed by all participants. Fifteen (50\%) students were male, and the median age was comparable between groups. Most candidates were right-handed; five candidates were left-handed (Table 1). Phase 1 took an average of $3 \mathrm{~h}$ to complete; phase 2 lasted an average of $1.5 \mathrm{~h}$ for both groups.

\section{Performance time}

Group A (3D) took less time overall (Table 2 and Fig. 2) to execute the FLS tasks compared with group B (task 1, $236 \mathrm{~s}$ vs $245.5 \mathrm{~s}$; task $2,368.4 \mathrm{~s}$ vs $500.8 \mathrm{~s}$; task $3,312.9 \mathrm{~s}$ vs $499.7 \mathrm{~s}$ ). These differences were statistically significant for task 2 $(P=0.02)$ and task $3(P<0.01)$.

\section{Mean error rate}

A lower mean error rate was observed in group A (task 1, 0 vs 0.2 ; task $2,0.4$ vs 1.8 ; task $3,0.24$ vs 1.1 ), with statistical significance noted for all three tasks $(P<0.01)$ (Table 3 and Fig. 3).

\section{Efficiency improvement}

Group B (2D) had a superior rate of improvement (\%) in task $1 \quad(P<0.001)$ and task $2(P=0.15)$ compared with group A (3D) $(248.8 \%$ vs $132.1 \%$ and $123.9 \%$ vs $139 \%$, respectively). In task 3 , group A (3D) demonstrated greater improvement, although this result did not attain statistical significance (190\% vs $173.1 \%, P=0.2)$ (Table 4 and Fig. 4). 
On direct questioning, 87\% (13 respondents) in group A preferred the $3 \mathrm{D}$ visual system, and $13 \%$ preferred the $2 \mathrm{D}$ visual system. The main reasons given for the preference for the 3D stereoscopic image included improved depth perception, better image definition, increased ease in judging distances, and improved spatial awareness. In total, $93 \%$ of the participants in group A either agreed or strongly agreed with the statement that 3D imaging facilitated improvement in their 2D performance, particularly for more complex tasks, such as intra-corporeal suturing.

\section{Discussion}

Three-dimensional imaging in laparoscopic surgery represents a major advance in technology, but remains an expensive endeavour at present. Although it is apparent that an improved visual system is likely to make most laparoscopic tasks more efficient, the availability of 3D imaging systems remains scarce in clinical practice.

We intended to assess whether training on a 3D-based platform improves subsequent skills on $2 \mathrm{D}$ systems, a potentially common scenario in contemporary surgical practice. Task 1 (peg transfer) is a skill aimed at developing hand-eye coordination and depth perception. Group A (3D) had a faster performance time. Although this was not statistically significant, a positive trend suggested that this group had

Table 1. Participant demographics

\begin{tabular}{lll}
\hline Parameters & $\begin{array}{l}\text { Group A } \\
(3 D / 2 D)\end{array}$ & $\begin{array}{l}\text { Group B } \\
(2 D / 2 D)\end{array}$ \\
\hline Gender (male/female) & $(8 / 7)$ & $(7 / 8)$ \\
Mean age (years) & 21.7 & 23.6 \\
Dexterity (right/left) & $(12 / 3)$ & $(13 / 2)$ \\
Uncorrected sight problems & 0 & 0 \\
Colour blindness & 0 & 1 \\
\hline
\end{tabular}

faster acquisition of skills. The error rate in group A was also significantly lower. However, the $2 \mathrm{D}$ group achieved better results in terms of efficiency improvement. Tasks 2 and 3 demonstrated similar results. Task 2 (pattern cutting) is a skill aimed at developing bimanual and dissection techniques, and task 3 (intra-corporeal suturing) is aimed at fostering more advanced laparoscopic techniques. Our results demonstrated that after a short period of training in $3 \mathrm{D}$, candidates had a faster performance time and a lower error rate, which were both statistically significant. This reflects that $3 \mathrm{D}$ training enhances the development of more complex tasks, where it may be particularly useful in the context of training. Although efficiency improvement did not attain significance for these more complex tasks, there was a trend towards this.

In a post-study questionnaire, participants from group A revealed a preference for the 3D system. Group A believed that their highest improvement was achieved in the intracorporeal suturing 3D model, which confirms previous evidence supporting the improved execution of complex tasks using stereoscopic vision.

There are presently no courses or training curricula for surgical simulation that include training with 3D laparoscopic platforms. Several studies, including the present one, have demonstrated the superiority of stereoscopic

Table 3. Differences between the 3D and 2D groups in the mean error rate

\begin{tabular}{llll}
\hline & \multicolumn{3}{l}{ Mean error rate (SD) (range) } \\
\cline { 2 - 4 } & $\begin{array}{l}\text { Task 1: } \\
\text { peg } \\
\text { transfer }\end{array}$ & $\begin{array}{l}\text { Task 2: } \\
\text { pattern } \\
\text { cutting }\end{array}$ & $\begin{array}{l}\text { Task 3: } \\
\text { intra-corporeal } \\
\text { suturing }\end{array}$ \\
\hline Group A (3D) & $0(0)$ & $0.4(0.3)(0-1)$ & $0.24(0.2)(0-0.7)$ \\
Group B (2D) & $0.2(0.3)(0-1)$ & $1.8(1.2)(0.33-5)$ & $1.1(0.5)(0.3-2)$ \\
$P$ value & $<0.01$ & $<0.01$ & $<0.01$ \\
\hline
\end{tabular}

Table 2. Differences between the $3 D$ and $2 D$ groups in performance time

\begin{tabular}{llll}
\hline & \multicolumn{2}{l}{ Performance time, s (SD) (range) } & \\
\cline { 2 - 4 } & Task 1: peg transfer & Task 2: pattern cutting & $\begin{array}{l}\text { Task 3: intra-corporeal } \\
\text { suturing }\end{array}$ \\
\hline Group A (3D) & $236(46.5)(164.7-306.3)$ & $368.4(175.1)(236.7-965.7)$ & $312.9(113.1)(143.3-596.7)$ \\
Group B (2D) & $245.5(49.5)(171-332)$ & $500.7(155.9)(286-744)$ & $499.7(195.5)(249.7-897)$ \\
$P$ value & 0.28 & 0.02 & $<0.01$ \\
\hline
\end{tabular}


vision over standard 2D laparoscopic surgery for skill acquisition. $^{2,5,15}$ These results can therefore serve as supporting evidence for the establishment of a new and promising way to teach laparoscopic surgical skills, shorten the learning curve for this technique, and possibly reduce errors in clinical practice, thereby leading to improved patient care and safety.

It is evident, both in our study and in the literature, that a combination of both $3 \mathrm{D}$ and $2 \mathrm{D}$ training platforms used in conjunction provide a superior learning experience to trainees. Given that most surgical units utilise $2 \mathrm{D}$ systems in their day-to-day practice, it is essential that trainees are familiar with the constraints of operating with this system. However, by introducing 3D laparoscopic platforms in the training setting, the ease of developing transferable skills is improved. This is particularly true for more complex tasks, such as fine dissection and suturing, where a $3 \mathrm{D}$ view makes a significant difference in depth perception, especially in the

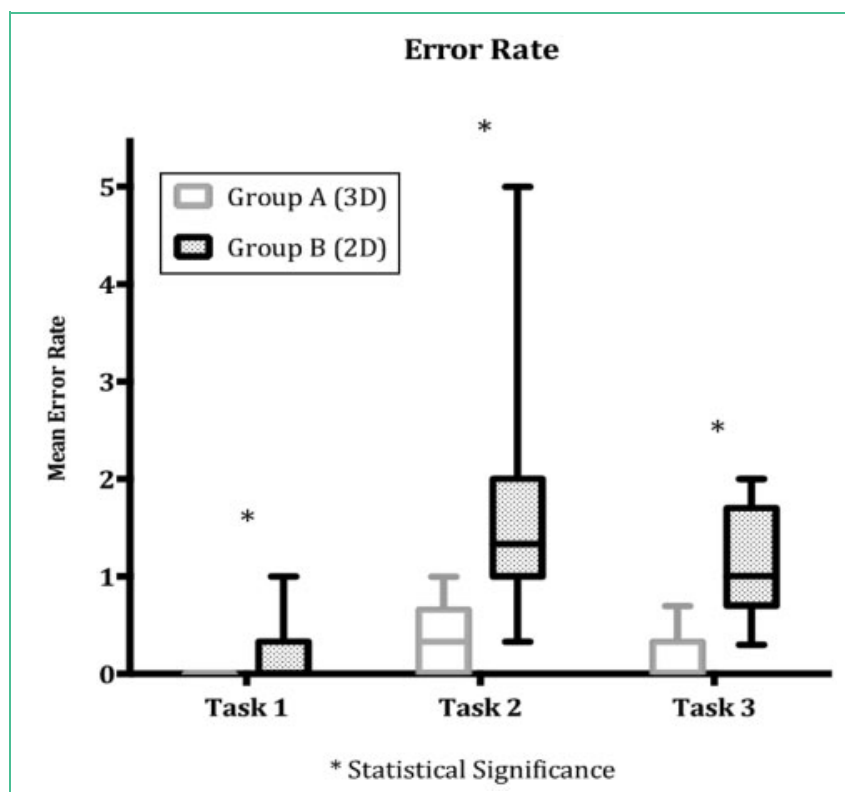

Figure 3. Differences in the mean error rate between the $3 \mathrm{D}$ and $2 \mathrm{D}$ trained groups. early stages of training. Thus, based on our experience, we propose a curriculum that comprises both $3 \mathrm{D}$ and $2 \mathrm{D}$ laparoscopic training, with approximately $25 \%$ to $50 \%$ of initial training time spent utilising a 3D simulation platform. This will ensure that trainees are exposed to the normal laparoscopic set-up that they will be expected to utilise in future practice, yet can develop skills in a sequential manner, particularly more complex tasks, utilising a 3D system. These skills are, as our study has demonstrated, transferable to a standard 2D platform. The usefulness of this approach was assessed with a post-study questionnaire, and most of the candidates concurred that a combined approach was useful for meeting their training requirements.

\section{Limitations}

Although this study aimed to assess novices with a view to developing a basic training curriculum, a further study that

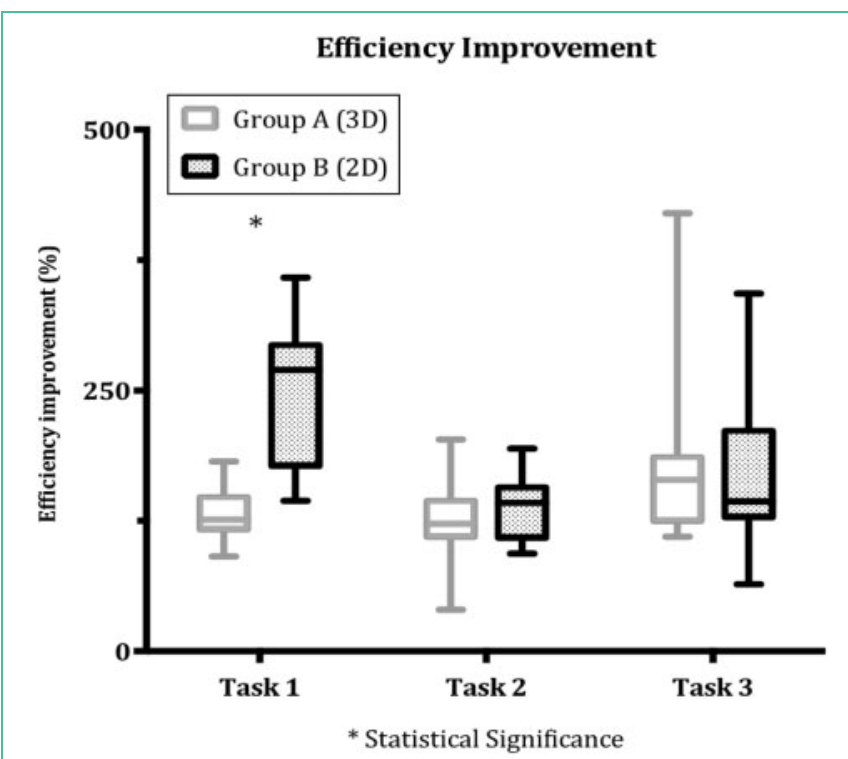

Figure 4. Differences in efficiency improvement between the 3D and $2 \mathrm{D}$ trained groups.

Table 4. Differences between the $2 D$ and $3 D$ groups in efficiency improvement from phase 1 to phase 2

\begin{tabular}{llll}
\hline & \multicolumn{2}{c}{ Efficiency improvement, \% (SD) (range) } & \\
\cline { 2 - 3 } & Task 1: peg transfer & Task 2: pattern cutting & \multicolumn{1}{c}{$\begin{array}{l}\text { Task 3: intra-corporeal } \\
\text { suturing }\end{array}$} \\
\hline Group A (3D) & $132.1(24)(90.9-182)$ & $123.9(34.8)(40-202.5)$ & $190(98.1)(109.7-419.5)$ \\
Group B (2D) & $248.8(66.8)(144.3-358.3)$ & $139(31.2)(93.7-194.5)$ & $173.1(78.5)(64.5-343.1)$ \\
$P$ value & $<0.01$ & 0.15 & 0.2 \\
\hline
\end{tabular}


assesses surgical trainees with different platforms would also be useful. Stereoscopic vision requires an adaptation period to adjust to the static environment of a box simulator, which has fewer contours and colours than the abdominal cavity. This adaptation is likely to be absent or much shorter in the clinical setting, thereby further improving the user's performance time. Thus, although extremely useful in learning the basics of laparoscopy, the ideal training setting is in the operating theatre. Finally, the challenges of static navigation and the limitations of the model itself could have influenced the outcomes of this or any other laboratory-based study.

In summary, 3D technology enables a more rapid and easier method of developing complex laparoscopic skills, which can be transferred into routine $2 \mathrm{D}$ practice with improved performance time and efficiency, with a reduced error rate.

\section{Conflict of interest}

The authors have no conflicts of interest or financial ties to disclose.

\section{Acknowledgements}

This study was funded by Barts Cancer Institute, Queen Mary University of London, Charterhouse Square, London EC1M 6BQ, UK.

\section{References}

1. Wagner OJ, Hagen M, Kurmann A, Horgan S, Candinas D, Vorburger SA. Three-dimensional vision enhances task performance independently of the surgical method. Surg Endosc 2012; 26: 2961-2968. https://doi.org/10.1007/s00464-0122295-3.

2. Alaraimi B, El Bakbak W, Sarker S, Makkiyah S, AlMarzouq A, Goriparthi R, et al. A randomized prospective study comparing acquisition of laparoscopic skills in threedimensional (3D) vs. two-dimensional (2D) laparoscopy. World J Surg 2014; 38: 2746-2752. https://doi.org/10.1007/ s00268-014-2674-0.

3. Subramonian K, DeSylva S, Bishai P, Thompson P, Muir G. Acquiring surgical skills: a comparative study of open versus laparoscopic surgery. Eur Urol 2004; 45: 346-351. https://doi. org/10.1016/j.eururo.2003.09.021.

4. Heemskerk J, Zandbergen R, Maessen JG, Greve JWM, Bouvy ND. Advantages of advanced laparoscopic systems. Surg Endosc 2006; 20: 730-733. https://doi.org/10.1007/ s00464-005-0456-3.

5. Ashraf A, Collins D, Whelan M, O'Sullivan R, Balfe P. Threedimensional (3D) simulation versus two-dimensional (2D) enhances surgical skills acquisition in standardised laparoscopic tasks: a before and after study. Int J Surg 2015; 14 : 12-16. https://doi.org/10.1016/j.ijsu.2014.12.020.

6. Hubber JW, Taffinder N, Russell RCG, Darzi A. The effects of different viewing conditions on performance in simulated minimal access surgery. Ergonomics 2003; 46: 999-1016. https://doi.org/10.1080/0014013031000109197.

7. Gallagher AG, Ritter EM, Lederman AB, McClusky DA, Smith CD. Video-assisted surgery represents more than a loss of three-dimensional vision. Am J Surg 2005; 189: 76-80. https://doi.org/10.1016/j.amjsurg.2004.04.008.

8. Chua R, Elliott D. Visual regulation of manual aiming. Hum Mov Sci 1993; 12: 365-401. https://doi.org/10.1016/ 0167-9457(93)90026-L.

9. Taffinder N, Smith SGT, Huber J, Russell RCG, Darzi A. The effect of a second-generation 3D endoscope on the laparoscopic precision of novices and experienced surgeons. Surg Endosc 1999; 13: 1087-1092. https://doi.org/10.1007/ s004649901179.

10. Perkins N, Starkes JL, Lee TD, Hutchison C. Learning to use minimal access surgical instruments and 2-dimensional remote visual feedback: how difficult is the task for novices? Adv Health Sci Educ 2002; 7: 117-131. https://doi.org/10. 1023/A:1015700526954.

11. Berguer R, Smith WD, Chung YH. Performing laparoscopic surgery is significantly more stressful for the surgeon than open surgery. Surg Endosc 2001; 15: 1204-1207. https://doi. org/10.1007/s004640080030.

12. Gofrit ON, Mikahail AA, Zorn KC, Zagaja GP, Steinberg GD, Shalhav AL. Surgeons' perceptions and injuries during and after urologic laparoscopic surgery. Urology 2008; 71: 404-407. https://doi.org/10.1016/j.urology.2007.07.077.

13. LaGrange CA, Clark CJ, Gerber EW, Strup SE. Evaluation of three laparoscopic modalities: robotics versus three-dimensional vision laparoscopy versus standard laparoscopy. J Endourol 2008; 22: 511-516. https://doi.org/10.1089/end. 2007.0241.

14. Bhayani SB, Andriole GL. Three-dimensional (3D) vision: does it improve laparoscopic skills? An assessment of a 3D head-mounted visualization system. Rev Urol 2005; 7: 211-214. PMCID: PMC1477587.

15. Votanopoulos K, Brunicardi FC, Thornby J, Bellows CF. Impact of three-dimensional vision in laparoscopic training. World J Surg 2008; 32: 110-118. https://doi.org/10.1007/ s00268-007-9253-6.

16. Smith R, Day A, Rockall T, Ballard K, Bailey M, Jourdan I. Advanced stereoscopic projection technology significantly improves novice performance of minimally invasive surgical skills. Surg Endosc 2012; 26: 1522-1527. https://doi.org/10. 1007/s00464-011-2080-8.

17. Seymour NE, Gallagher AG, Roman SA, O’Brien MK, Bansal VK, Andersen DK, et al. Virtual reality training 
improves operating room performance: results of a randomized, double-blinded study. Ann Surg 2002; 236: 458-463. https://doi.org/10.1097/01.SLA.0000028969.51489.B4.

18. Mistry M, Roach VA, Wilson TD. Application of stereoscopic visualization on surgical skill acquisition in novices. J Surg Educ 2013; 70: 563-570. https://doi.org/10.1016/j.jsurg.2013.04.006.

19. Held RT, Hui TT. A guide to stereoscopic 3D displays in medicine. Acad Radiol 2011; 18: 1035-1048. https://doi. org/10.1016/j.acra.2011.04.005.

20. Kong SH, Oh BM, Yoon H, Ahn HS, Lee HJ, Chung SG, et al. Comparison of two- and three-dimensional camera systems in laparoscopic performance: a novel 3D system with one camera. Surg Endosc 2010; 24: 1131-1143. https://doi.org/10. 1007/s00464-009-0740-8.

21. Storz P, Buess GF, Kunert W, Kirschniak A. 3D HD versus 2D HD: surgical task efficiency in standardised phantom tasks. Surg Endosc 2012; 26: 1454-1460. https://doi.org/10. 1007/s00464-011-2055-9.

22. Patel HRH, Ribal MJ, Arya M, Nauth-Misir R, Joseph JV. Is it worth revisiting laparoscopic three-dimensional visualization? A validated assessment. Urology 2007; 70: 47-49. https://doi. org/10.1016/j.urology.2007.03.014.

23. Hanna GB, Shimi SM, Cuschieri A. Randomised study of influence of two-dimensional versus three-dimensional imaging on performance of laparoscopic cholecystectomy. Lancet 1998; 351: 248-251. https://doi.org/10.1016/S0140-6736(97)08005-7.

24. Bilgen K, Ustun M, Karakahya M, Isik S, Sengul S, Cetinkunar S, et al. Comparison of 3D imaging and 2D imaging for performance time of laparoscopic cholecystectomy. Surg Laparosc Endosc Percutan Tech 2013; 23: 180-183. https://doi.org/10.1097/SLE.0b013e3182827e17.

25. Ohuchida K, Kenmotsu H, Yamamoto A, Sawada K, Hayami T, Morooka K, et al. The effect of CyberDome, a novel 3-dimensional dome-shaped display system, on laparoscopic procedures. Int J Comput Assist Radiol Surg 2009; 4: 125-132. https://doi.org/10.1007/s11548-009-0282-5.

26. Kobayashi E, Ando T, Yamashita H, Sakuma I, Fukuyo T, Ando $\mathrm{K}$, et al. A high-resolution, three-dimensional thin endoscope for fetal surgery. Surg Endosc 2009; 23: 2450-2453. https://doi.org/10.1007/s00464-009-0413-7.

27. Tanagho YS, Andriole GL, Paradis AG, Madison KM, Sandhu GS, Varela JE, et al. 2D versus 3D visualization: impact on laparoscopic proficiency using the Fundamentals Of Laparoscopic Surgery skill set. J Laparoendosc Adv Surg Tech 2012; 22: 865-870. https://doi.org/10.1089/lap.2012.0220.

28. Ritter EM, Scott DJ. Design of a proficiency-based skills training curriculum for the fundamentals of laparoscopic surgery. Surg Innov 2007; 14: 107-112. https://doi.org/10.1177/ 1553350607302329.

29. Birkett DH, Josephs LG, Este-McDonald J. A new 3D laparoscope in gastrointestinal surgery. Surg Endosc 1994; 8: 1448-1451. https://doi.org/10.1007/BF00187357.

30. Rooney DM, Santos BF, Hungness ES. Fundamentals of laparoscopic surgery (FLS) manual skills assessment: surgeon vs nonsurgeon raters. J Surg Educ 2012; 69: 588-592. https://doi.org/10.1016/j.jsurg.2012.06.001.

31. Derossis AM, Fried GM, Abrahamowicz M, Sigman HH, Barkun JS, Meakins JL. Development of a model for training and evaluation of laparoscopic skills. Am J Surg 1998; 175: 482-487. https://doi.org/10.1016/S0002-9610(98) 00080-4.

32. Scott DJ, Ritter EM, Tesfay ST, Pimentel EA, Nagji A, Fried GM. Certification pass rate of $100 \%$ for fundamentals of laparoscopic surgery skills after proficiency-based training. Surg Endosc 2008; 22: 1887-1893. https://doi.org/10.1007/ s00464-008-9745-y. 